\title{
Pertumbuhan Stek Batang Pohpohan (Pilea trinervia Wight.) pada Umur Tanaman, Bagian Batang, dan Media Tanam yang Berbeda
}

\author{
The Growth of Pohpohan (Pilea trinervia Wight.) Stem Cuttings at Different Age, Stem Part, \\ and Growing Media.
}

\author{
Nicha Muslimawati ${ }^{1}$, Ketty Suketi $^{1}{ }^{*}$, dan Anas D. Susila ${ }^{1}$ \\ Diterima 15 April 2015 / Disetujui 26 Juni 2015
}

\begin{abstract}
Pohpohan (Pilea trinervia Wight.) is one of indigenous vegetables that grows in the mountain areas of West Java. Propagule availability in large quantities and in a short time can be done with cuttings. However, propagation of Pohpohan by cutting has not been developed presently. The objective of the research was to obtain the best plant age, stem part, and growing media for the growth of pohpohan stem cuttings. The research was conducted at the Center of Tropical Horticulture Studies Experimental Field Tajur-Bogor, from January to July 2013. The cuttings were taken from mother plants of 3, 4, 5, and 6 months, then the cuttings were cut to stem tips (B1), central stem (B2), and stem base (B3). The were five cuttings per experimental unit. Experiment were replicated 3 times. Cuttings were planted in polybag containing topsoil media (M0), rockwool (M1), husk and compost (M2), and vermicompost (M3). The experiment was arranged in Randomized Completely Block Design. Result of experiment showed that pohpohan from 4 month mother plant cut at stem base grow in husk and compost grow best $199.06 \%$ of living percentages, $100 \%$ percentage of rooted cutting and 11-12 number of leaves). The cutting of stem tips grown in husk and compost showed the highest mean for the increase of stem length, $3.94 \mathrm{~cm}$. There were no interaction between growing media of stem cuttings and part of stem in the growth of shoot height, number of branch, leaf width, and diameter of stem.
\end{abstract}

Key words: growing media, indigenous, pohpohan, stem cuttings

\begin{abstract}
ABSTRAK
Pohpohan (Pilea trinervia Wight.) merupakan salah satu sayuran indigenous yang banyak tumbuh di daerah pegunungan Jawa Barat. Pemenuhan kebutuhan bibit pohpohan dalam jumlah yang banyak dan dalam waktu yang singkat dapat dilakukan dengan perbanyakan vegetatif stek. Namun demikian perbanyakan stek pada pohpohan belum banyak dikembangkan untuk saat ini. Tujuan penelitian ini ialah memperoleh umur bahan tanaman, bagian batang, dan media tanam yang terbaik untuk pertumbuhan stek batang pohpohan. Penelitian dilaksanakan di Kebun Percobaan Pusat Kajian Hortikultura Tropika (PKHT) Tajur-Bogor, dari Januari sampai Juli 2013. Pohpohan yang digunakan yaitu berumur 3, 4, 5, dan 6 bulan, kemudian dilakukan stek batang pada bagian pucuk (B1), tengah (B2), dan pangkal (B3). Rancangan percobaan yang digunakan ialah rancangan kelompok lengkap teracak. Setiap satuan percobaan terdiri atas lima stek, percobaan terdiri atas tiga ulangan. Stek dimasukkan ke dalam polibag dengan media tanam topsoil (M0), rockwool (M1), arang sekam dan kompos (M2), serta kascing (M3). Hasil penelitian menunjukkan bahwa stek pohpohan yang berasal dari tanaman 4 bulan, bagian pangkal batang dan ditanam pada media arang sekam dan kompos memiliki pertumbuhan yang terbaik dengan rata-rata persentase hidup $99.06 \%$, persentase berakar 100\%, dan jumlah daun 11-12 helai. Stek pada pucuk batang yang ditanam pada media arang sekam dan kompos memiliki penambahan panjang batang stek $3.94 \mathrm{~cm}$. Tidak terdapat
\end{abstract}

${ }^{1}$ Departemen Agronomi dan Hortikultura, Fakultas Pertanian, Institut Pertanian Bogor (Bogor Agricultural University), Jl. Meranti, Kampus IPB Darmaga, Bogor 16680, Indonesia

Telp.\&Faks.62-251-8629353.*Email korespondensi: kettysuketi@yahoo.com 
interaksi antara perlakuan stek pada media tanam dengan bagian batang terhadap perumbuhan tinggi tunas, jumlah cabang, lebar daun, dan diameter batang.

Kata kunci: indigenous, media tanam, pohpohan, stek batang

\section{PENDAHULUAN}

Indonesia merupakan negara tropis yang menghasilkan berbagai macam sayuran. Salah satu sayuran yang tumbuh subur di Indonesia adalah sayuran indigenous. Sayuran indigenous adalah sayuran asli suatu daerah di Indonesia yang berasal dari daerah atau ekosistem tertentu, termasuk spesies pendatang dari wilayah geografis lain yang telah berevolusi dengan iklim dan geografis wilayah Indonesia. Sayuran indigenous disebut juga sayuran lokal (Balitsa, 2007).

Pohpohan merupakan salah satu sayuran indigenous yang banyak tumbuh di daerah pegunungan Jawa Barat. Daun pohpohan sering dikonsumsi masyarakat dalam keadaan segar karena memiliki aroma yang khas dan berbau harum. Di Jawa Barat sayuran ini dapat diperoleh di pasar tradisional dan supermarket. Sementara itu, daun pohpohan yang biasanya dikonsumsi hanya diperoleh dari kebun rumah yang berskala kecil. Pohpohan dapat tumbuh di daerah cerah atau di daerah teduh dan dapat tumbuh sebagai penutup tanah (Mahyar, 1994).

Menurut Balitsa (2007) pada umumnya pohpohan diperbanyak menggunakan biji, tetapi terdapat beberapa kendala, yaitu perbanyakan melalui biji (perkecambahan benih) membutuhkan waktu yang relatif lama, selain itu kondisi benih yang rekalsitran menyebabkan benih pohpohan tidak dapat disimpan terlalu lama. Menurut Muchtadi (2000) hal ini tidak seimbang dengan permintaan produksi bibit pohpohan yang terus meningkat.

Stek merupakan teknik perbanyakan alternatif dalam upaya pemenuhan kebutuhan bibit, dilakukan dengan cara melakukan pemisahan atau pemotongan bagian batang, akar atau daun dari pohon induknya. Penelitian Rahmania dan Kurniawati (2014) menunjukkan bahwa ukuran stek dengan jumlah buku yang beberbeda dapat meningkatkan produksi tanaman. Santoso et al. (2008) melaporkan bahwa pertumbuhan dan stek hidup terbaik pada jarak pagar diperoleh pada stek dengan panjang $20-30 \mathrm{~cm}$ dan diameter $2.0-2.4 \mathrm{~cm}$.
Perbanyakan yang dilakukan dengan cara stek akan terbentuk individu baru dengan genotipe sama dengan induknya (Hartmann dan Kester, 2002). Tujuan penelitian ini ialah mendapatkan umur bahan tanaman bahan tanaman bagian batang dan media yang terbaik untuk mendukung pertumbuhan stek pohpohan.

\section{BAHAN DAN METODE}

Penelitian dilaksanakan di Kebun Percobaan Pusat Kajian Hortikultura Tropika (PKHT) Tajur, Bogor, pada bulan Januari hingga Juli 2013. Bahan yang digunakan yaitu bibit pohpohan yang berumur 3, 4, 5, dan 6 bulan. Media tanam yang digunakan yaitu topsoil, rockwool, campuran arang sekam, dan kompos, serta kascing. Rootone F digunakan sebagai hormon pemacu tumbuhnya akar.

Rancangan yang digunakan ialah Rancangan Kelompok Lengkap Teracak (RKLT) yang disusun secara faktorial dengan dua faktor, yaitu bagian batang dan media tanam. Faktor pertama yaitu bagian batang (B) yang terdiri 3 taraf perlakuan, yaitu pucuk (B1), tengah (B2), dan pangkal (B3). Faktor kedua yaitu media tanam (M) yang terdiri dari 4 taraf perlakuan, yaitu topsoil (M0), rockwool (M1), arang sekam dan kompos (M2), dan kascing (M3). Percobaan disusun dengan 5 stek masing-masing satuan percobaan dan diulang sebanyak 3 kali, sehingga terdapat 36 satuan percobaan. Analisis statistik menggunakan Uji F dan dilakukan uji lanjut Duncan Multiple Range Test (DMRT) pada taraf 5\%.

Pelaksanaan percobaan meliputi persiapan bahan dan alat, stek batang pohpohan, pengamatan, dan pemeliharaan tanaman. Tanaman pohpohan yang berumur $3,4,5$, dan 6 bulan dijadikan bahan tanam kemudian dilakukan pemotongan stek batang menjadi bagian pucuk (B1), tengah (B2), dan pangkal (B3) dengan panjang stek $\pm 7 \mathrm{~cm}$. Media tanam yang digunakan yaitu topsoil (M0), rockwool (M1), arang sekam dan kompos (M2) 1:1, dan kascing (M3) dimasukan kedalam polibag berukuran 10 x $10 \mathrm{~cm}$. Media rockwool 
sebelumnya dipotong berbentuk persegi dengan sisi $\pm 5 \mathrm{~cm}$ dan dimasukkan ke dalam tray. Masing-masing stek dalam polibag dan tray dimasukkan dalam rumah pembibitan yang telah dipasang plastik dan paranet $75 \%$.

Pengamatan yang dilakukan yaitu persentase hidup, persentase berakar, tinggi tunas, jumlah cabang, jumlah daun, lebar daun, pertambahan panjang batang, dan diameter batang. Pemeliharaan tanaman yang dilakukan yaitu penyiraman, pemupukan pada 3 MST menggunakan pupuk NPK Mutiara $\left(24 \mathrm{~g} \mathrm{~L}^{-1}\right)$ dengan cara dikocor, penyiangan atau pencabutan gulma, serta pengendalian hama penyakit tanaman. Frekuensi penyiraman dilakukan 1-2 hari sekali. Penyiangan atau pencabutan gulma dilakukan di sekitar area pembibitan.

\section{HASIL DAN PEMBAHASAN}

\section{Kondisi Umum}

Percobaan dilakukan di rumah pembibitan Kebun Tajur, Bogor. Menurut BMKG (2013) ketinggian daerah Tajur, Bogor yaitu $\pm 250 \mathrm{~m}$ diatas permukaan laut. Curah hujan saat percobaan antara 91.5-497 mm bulan ${ }^{-1}$ dengan rata-rata $385.9 \mathrm{~mm}^{\text {bulan }}{ }^{-1}$, sedangkan suhu rata-rata antara $26-27.8{ }^{0} \mathrm{C}$ dan kelembaban udara rata-rata mencapai $84.2 \%$.

Pada saat percobaan terdapat sedikit kendala seperti adanya penyakit yang menyerang stek batang $\pm 5 \%$ dan adanya cendawan pada media rockwool. Penyakit yang rawan menyerang pada stek batang pohpohan adalah busuk batang, penyakit ini menyebabkan batang berwarna kehitaman dan berbau.
Penyakit busuk batang ditandai dengan berubahnya warna batang menjadi coklat kehitaman, kemudian diameter batang mengecil dan mengakibatkan kematian. Gulma yang sering ditemukan tumbuh di polibag yaitu gulma jenis rumput. Pengendalian gulma dilakukan dengan mencabut gulma yang tumbuh sehingga tidak mengganggu tanaman pohpohan.

\section{Umur Tanaman}

Bahan tanam yang digunakan yaitu pohpohan berumur 3, 4, 5, dan 6 bulan yang berasal dari Calobak, Bogor. Pada pengamatan minggu terakhir (6 MST) diketahui bahwa bahan tanam yang memiliki nilai rata-rata persentase hidup, persentase berakar, jumlah daun, dan panjang batang tertinggi yaitu bahan tanam pohpohan berumur 4 bulan. Hal ini menunjukkan bahwa pohpohan yang berumur 4 bulan dapat dijadikan sebagai bahan tanam terbaik untuk pertumbuhan stek batang. Oleh karena itu, data yang digunakan pada hasil dan pembahasan ini adalah bahan tanam pohpohan yang berumur 4 bulan. Menurut Hartmann dan Kester (2002) umur bahan tanam merupakan salah satu faktor terpenting dalam perbanyakan stek. Umur tanaman yang terlalu tua atau terlalu muda menyebabkan stek gagal berkembang.

Stek batang yang berasal dari pohpohan berumur 4 bulan menunjukkan rata-rata persentase hidup $99.06 \%$, persentase berakar $100 \%$, jumlah daun 9-10 helai, pertambahan panjang batang $3.87 \mathrm{~cm}$, dan diameter batang $1.35 \mathrm{~cm}$. Nilai rata-rata pertumbuhan stek batang yang berasal dari pohpohan berumur 4 bulan disajikan pada Tabel 1.

Tabel 1. Pertumbuhan stek batang pohpohan pada 6 MST

\begin{tabular}{lcccc}
\hline \multirow{2}{*}{ Peubah } & \multicolumn{3}{c}{ Umur Bahan Tanam (Bulan) } \\
\cline { 2 - 5 } & 3 & 4 & 5 & 6 \\
\hline Persentase hidup (\%) & $98.12 \mathrm{~b}$ & $99.06 \mathrm{a}$ & $96.31 \mathrm{~b}$ & $94.19 \mathrm{~b}$ \\
Persentase berakar (\%) & 100 & 100 & 100 & 100 \\
Tinggi tunas (cm) & $6.03 \mathrm{ab}$ & $6.12 \mathrm{a}$ & $5.27 \mathrm{ab}$ & $5.16 \mathrm{c}$ \\
Jumlah cabang & $1.51 \mathrm{ab}$ & $2.49 \mathrm{a}$ & $1.38 \mathrm{abc}$ & $1.20 \mathrm{bc}$ \\
Jumlah daun (helai) & $9.16 \mathrm{ab}$ & $11.83 \mathrm{a}$ & $8.46 \mathrm{bc}$ & $8.13 \mathrm{c}$ \\
Lebar daun (cm) & $2.34 \mathrm{abc}$ & $2.86 \mathrm{a}$ & $2.08 \mathrm{bc}$ & $2.27 \mathrm{~b}$ \\
Pertambahan panjang batang (cm) & $3.21 \mathrm{ab}$ & $3.87 \mathrm{a}$ & $3.09 \mathrm{~b}$ & $3.13 \mathrm{~b}$ \\
Diameter batang & $1.17 \mathrm{ab}$ & $1.35 \mathrm{a}$ & $1.14 \mathrm{ab}$ & $1.09 \mathrm{~b}$ \\
\hline
\end{tabular}

Keterangan: Angka-angka pada baris yang sama yang diikuti oleh huruf yang sama tidak berbeda nyata pada taraf uji $5 \%$ (uji selang berganda Duncan). 


\section{Persentase Hidup dan Berakar}

Persentase hidup pada stek batang diamati mulai dari 1 MST sampai dengan 6 MST. Tabel 2 menunjukkan bahwa perlakuan bagian batang dan media tanam mempengaruhi pertumbuhan stek pada 6 MST. Stek pada bagian pangkal batang (B3) memiliki nilai tertinggi yaitu $99.23 \%$. Stek batang pohpohan yang ditanam pada media arang sekam dan kompos (M2) memiliki nilai tertinggi yaitu $99.35 \%$.

Media arang sekam dapat meningkatkan C-organik, $\mathrm{N}$ total, $\mathrm{pH}$ dan $\mathrm{P}$ tersedia sehingga dapat menjadikan media tanam arang sekam gembur tetapi cenderung mudah lapuk. Arang sekam juga merupakan bahan organik yang dapat dijadikan sebagai sumber energi bagi perkembangan jasad renik tanah sehingga jumlah $\mathrm{CO}_{2}$ yang dihasilkan menjadi cenderung meningkat (Ismail et al., 2011). Penelitian Arinda (2010) mengenai pengaruh berbagai komposisi arang sekam dan kompos (1:3, 1:1, 3:1) sebagai media pertumbuhan sorgum menunjukkan bahwa kombinasi arang sekam dan kompos (1:1) adalah yang terbaik untuk persentase hidup sorgum.

Persentase berakar diamati pada akhir percobaan, yaitu 6 MST. Hal ini bertujuan untuk memperkecil kemungkinan stek mati. Perlakuan bagian batang dan media tanam memiliki persentase berakar $100 \%$, hal ini menunjukkan bahwa perlakuan bagian batang dan media tanam mempengaruhi persentase stek berakar. Interaksi antara bagian batang dan media tanam menunjukkan hasil yang baik pada persentase berakar. Hal ini berarti stek batang bagian pucuk, tengah, dan pangkal yang ditanam pada media topsoil, rockwool, arang sekam dan kompos, serta kascing mempengaruhi persentase stek berakar (Tabel 2). Menurut Hartmann dan Kester (2002) perkembangan akar yang baik dapat mengimbangi dan sekaligus mendukung pertumbuhan dan perkembangan tajuk bibit yang baik pula.

Interaksi stek batang bagian pangkal dengan media topsoil, rockwool, arang sekam dan kompos, serta kascing memiliki persentase hidup tertinggi yaitu 99.20\%, 97.73\%, $99.81 \%$, dan $99.60 \%$. Stek batang bagian pucuk yang ditanam pada media rockwool menunjukkan persentase hidup yang paling kecil dengan nilai persentase $96.41 \%$ (Tabel 3). Hal ini diduga karena adanya cendawan dan ketidakstabilan $\mathrm{pH}$ pada rockwool yang mempengaruhi pertumbuhan stek. Menurut Landis dan Morgan (2009) rockwool memiliki $\mathrm{pH}$ 6.0-7.0, sedangkan untuk pertumbuhan tanaman memerlukan $\mathrm{pH}$ sekitar 5.0-5.5. Nilai $\mathrm{pH}$ yang tidak stabil dapat mempengaruhi pertumbuhan tanaman.

Tabel 2. Persentase hidup dan berakar stek batang pohpohan berumur 4 bulan pada perlakuan bagian batang dan media tanam

\begin{tabular}{|c|c|c|c|c|c|c|c|}
\hline \multirow{3}{*}{ Perlakuan } & \multicolumn{6}{|c|}{ Persen Hidup (\%) } & \multirow{3}{*}{$\begin{array}{c}\text { Persen Berakar (\%) } \\
6\end{array}$} \\
\hline & \multicolumn{6}{|c|}{ Waktu (MST) } & \\
\hline & 1 & 2 & 3 & 4 & 5 & 6 & \\
\hline \multicolumn{8}{|l|}{ Bagian batang } \\
\hline Pucuk & 98.1 & 98.1 & 98.3 & 98.2 & 98.2 & $98.4 b$ & 100 \\
\hline Tengah & 98.5 & 98.5 & 98.5 & 98.7 & 98.8 & $98.9 \mathrm{~b}$ & 100 \\
\hline Pangkal & 99.4 & 99.4 & 99.4 & 99.2 & 99.3 & $99.2 \mathrm{a}$ & 100 \\
\hline $\mathrm{Uji} F$ & tn & tn & tn & tn & tn & $* *$ & \\
\hline \multicolumn{8}{|l|}{ Media } \\
\hline Topsoil & 99.5 & 99.6 & 99.7 & 99.8 & 98.3 & $98.5 \mathrm{ab}$ & 100 \\
\hline Rockwool & 98.3 & 98.4 & 98.5 & 98.7 & 97.4 & $97.2 b$ & 100 \\
\hline AS+kompos & 100.0 & 97.0 & 97.1 & 97.4 & 99.0 & $99.4 \mathrm{a}$ & 100 \\
\hline Kascing & 99.8 & 99.8 & 98.3 & 98.4 & 98.5 & $98.7 \mathrm{ab}$ & 100 \\
\hline $\mathrm{Uji}^{\mathrm{F}}$ & th & tn & tn & tn & tn & $*$ & $* *$ \\
\hline Interaksi & th & tn & th & tn & tn & ** & ** \\
\hline
\end{tabular}


Tabel 3. Interaksi antara bagian batang dengan media tanam terhadap persen hidup dan persen berakar stek batang pohpohan berumur 4 bulan pada $6 \mathrm{MST}$

\begin{tabular}{lccll}
\hline \multirow{2}{*}{$\begin{array}{l}\text { Bagian } \\
\text { batang }\end{array}$} & $\mathrm{T}$ & $\mathrm{R}$ & ASK & $\mathrm{K}$ \\
\cline { 2 - 5 } & & & & \\
\hline Pucuk & 98.7 & 96.4 & $99.6 \mathrm{ab}$ & $98.6 \mathrm{ab}$ \\
Tengah & 98.7 & 96.5 & $99.0 \mathrm{ab}$ & $99.3 \mathrm{ab}$ \\
Pangkal & 99.2 & 97.7 & $99.8 \mathrm{a}$ & $99.6 \mathrm{a}$ \\
$\mathrm{P}$ & th & th & $* *$ & $*$ \\
\hline & \multicolumn{5}{c}{ Persentase Berakar $(\%)$} \\
Pucuk & 100 & 100 & 100 & 100 \\
Tengah & 100 & 100 & 100 & 100 \\
Pangkal & 100 & 100 & 100 & 100 \\
$\mathrm{P}$ & $* *$ & $* *$ & $* *$ & $* *$ \\
\hline
\end{tabular}

Keterangan: AS: Arang sekam. *: berpengaruh nyata pada taraf uji $5 \%$, **: berpengaruh sangat nyata pada taraf uji $1 \%$, tn: tidak berbeda nyata pada taraf uji 5\%. Angkaangka pada kolom yang sama yang diikuti oleh huruf yang sama tidak berbeda nyata pada taraf uji 5\% (uji selang berganda Duncan). $\mathrm{T}=$ Topsoil, $\mathrm{R}=$ Rockwool, ASK= Arang sekam + kompos, $\mathrm{K}=$ Kascing.

\section{Jumlah Daun}

Jumlah daun diamati dari 1 MST sampai dengan 6 MST. Pohpohan yang sering dimanfaatkan adalah bagian daun, rasanya yang khas dan berbau mint menjadikan daun pohpohan banyak dikonsumsi dalam keadaan segar. Perlakuan bagian batang dan media tanam mempengaruhi jumlah daun stek batang pohpohan berumur 4 bulan pada 5 MST dan 6 MST (Tabel 4).

Interaksi antara bagian batang dan media tanam pada 5 MST dan 6 MST menunjukkan stek batang bagian pangkal yang ditanam pada media topsoil, arang sekam dan kompos, serta kascing menunjukkan pengaruh yang paling baik terhadap pertumbuhan jumlah daun, sebanyak 10-11 helai, 12-13 helai, dan 10-11 helai. Stek batang bagian tengah yang ditanam pada media rockwool mempengaruhi jumlah daun sebanyak 5-6 helai (Tabel 5).

\section{Pertambahan Panjang Batang Stek}

Pertambahan panjang batang stek dihitung dari ujung batang sampai titik pangkal batang setiap minggunya. Perlakuan bagian batang dan media tanam mempengaruhi pertambahan panjang batang stek pada 6 MST (Tabel 6). Interaksi stek batang bagian pucuk yang ditanam pada media tanam topsoil, rockwol, arang sekam dan kompos, serta kascing mempengaruhi pertambahan panjang batang stek dengan nilai $2.62 \mathrm{~cm}, 1.28 \mathrm{~cm}, 3.94 \mathrm{~cm}$, dan $3.19 \mathrm{~cm}$ (Tabel 7). Hal ini sesuai dengan pendapat Santoso (2008) bahwa panjang batang stek lebih intensif pada stek yang memilki diameter batang kecil.

Tabel 4. Jumlah daun stek batang pohpohan berumur 4 bulan pada perlakuan bagian batang dan media tanam

\begin{tabular}{|c|c|c|c|c|c|c|}
\hline \multirow{2}{*}{ Perlakuan } & \multicolumn{6}{|c|}{ Waktu } \\
\hline & $1 \mathrm{MST}$ & $2 \mathrm{MST}$ & 3 MST & 4 MST & $5 \mathrm{MST}$ & $6 \mathrm{MST}$ \\
\hline Bagian batang & \multicolumn{6}{|c|}{ (Helai) } \\
\hline Pucuk & 2.2 & 4.3 & 6.3 & $6.7 \mathrm{~b}$ & $8.7 \mathrm{~b}$ & $9.1 \mathrm{~b}$ \\
\hline Tengah & 0.3 & 4.4 & 5.4 & $7.1 \mathrm{~b}$ & $8.2 \mathrm{~b}$ & $9.6 \mathrm{~b}$ \\
\hline Pangkal & 0.2 & 4.4 & 5.4 & $7.5 \mathrm{a}$ & $9.7 \mathrm{a}$ & $10.4 \mathrm{a}$ \\
\hline Uji F & tn & tn & $\operatorname{tn}$ & $*$ & $*$ & $* *$ \\
\hline \multicolumn{7}{|l|}{ Media } \\
\hline Topsoil & 2.3 & 4.7 & 6.7 & 7.5 & $9.5 \mathrm{ab}$ & $10.7 \mathrm{ab}$ \\
\hline Rockwool & 2.2 & 3.3 & 4.3 & 4.1 & $5.8 \mathrm{~b}$ & $5.9 \mathrm{c}$ \\
\hline AS+kompos & 2.2 & 4.4 & 6.4 & 8.0 & $10.1 \mathrm{a}$ & $13.0 \mathrm{a}$ \\
\hline Kascing & 2.4 & 4.5 & 6.5 & 7.9 & $9.9 \mathrm{ab}$ & $11.6 \mathrm{ab}$ \\
\hline Uji F & tn & tn & tn & tn & $*$ & $*$ \\
\hline Interaksi & tn & tn & tn & tn & * & ** \\
\hline
\end{tabular}


Tinggi Tunas, Jumlah Cabang, Lebar Daun, dan Diameter Batang

Hasil analisis ragam pertumbuhan stek batang pohpohan menunjukkan bahwa tidak terdapat interaksi antara bagian batang dan media tanam terhadap pertumbuhan tinggi tunas, jumlah cabang, lebar daun, dan diameter batang. Pada 5 MST stek bagian batang mempengaruhi tinggi tunas dan jumlah cabang, stek yang ditanam pada media tanam mempengaruhi pertumbuhan lebar daun dan diameter batang. Pada 6 MST, stek bagian batang mempengaruhi tinggi tunas, jumlah cabang, dan diameter batang, dan stek pada media tanam tidak mempengaruhi pertumbuhan tinggi tunas, jumlah cabang, lebar duan, dan diameter batang (Tabel 8).

Tabel 5. Interaksi antara stek bagian batang dan media tanam terhadap jumlah daun stek batang pohpohan berumur 4 bulan pada 5 MST dan 6 MST

\begin{tabular}{|c|c|c|c|c|}
\hline \multirow{2}{*}{ Bagian Batang } & Topsoil & Rockwool & $\begin{array}{l}\text { Arang Sekam } \\
+ \text { Kompos }\end{array}$ & Kascing \\
\hline & \multicolumn{4}{|c|}{$5 \mathrm{MST}$} \\
\hline Pucuk & $9.5 \mathrm{~b}$ & 5.1 & $11.1 \mathrm{~b}$ & $8.5 b$ \\
\hline Tengah & $9.7 \mathrm{~b}$ & 5.4 & $10.2 b$ & $9.6 \mathrm{~b}$ \\
\hline Pangkal & $10.8 \mathrm{a}$ & 5.4 & $12.2 \mathrm{a}$ & $9.7 \mathrm{a}$ \\
\hline \multirow[t]{2}{*}{$\mathrm{P}$} & $*$ & tn & $* *$ & $*$ \\
\hline & \multicolumn{4}{|c|}{$6 \mathrm{MST}$} \\
\hline Pucuk & $10.3 b$ & 5.5 & $11.8 \mathrm{~b}$ & $9.1 \mathrm{~b}$ \\
\hline Tengah & $10.1 \mathrm{~b}$ & 5.9 & $12.0 \mathrm{~b}$ & $10.2 b$ \\
\hline Pangkal & $10.4 \mathrm{a}$ & 6.0 & $12.6 \mathrm{a}$ & $10.3 \mathrm{a}$ \\
\hline $\mathrm{P}$ & * & tn & $* *$ & $* *$ \\
\hline
\end{tabular}

Keterangan: AS: Arang sekam. *: berpengaruh nyata pada taraf uji 5\%, **: berpengaruh sangat nyata pada taraf uji $1 \%$, tn: tidak berbeda nyata pada taraf uji $5 \%$. Angka-angka pada kolom yang sama yang diikuti oleh huruf yang sama tidak berbeda nyata pada taraf uji 5\% (uji selang berganda Duncan).

Tabel 6. Pertambahan panjang batang stek pohpohan berumur 4 bulan pada perlakuan bagian batang dan media tanam

\begin{tabular}{|c|c|c|c|c|c|c|}
\hline \multirow{2}{*}{ Perlakuan } & \multicolumn{6}{|c|}{ Waktu (MST) } \\
\hline & 1 & 2 & 3 & 4 & 5 & 6 \\
\hline Bagian batang & \multicolumn{6}{|c|}{$(\mathrm{cm})$} \\
\hline Pucuk & 0.06 & 0.09 & 2.07 & $2.10 \mathrm{a}$ & 3.79 & $3.62 \mathrm{a}$ \\
\hline Tengah & 0.12 & 0.35 & 1.44 & $1.57 \mathrm{ab}$ & 2.94 & $2.79 \mathrm{ab}$ \\
\hline Pangkal & 0.17 & 0.29 & 1.12 & $1.48 b$ & 2.86 & $2.76 a b$ \\
\hline Uji F & tn & tn & tn & * & tn & $* *$ \\
\hline Media & & & & & & \\
\hline Topsoil & 0.12 & 0.17 & 1.07 & 2.08 & $1.02 \mathrm{a}$ & $1.07 \mathrm{ab}$ \\
\hline Rockwool & 0.07 & 0.29 & 0.13 & 0.02 & $0.34 \mathrm{~b}$ & $0.09 \mathrm{c}$ \\
\hline AS+kompos & 0.19 & 0.17 & 1.07 & 2.06 & $0.94 a b$ & $1.39 \mathrm{a}$ \\
\hline Kascing & 0.04 & 0.11 & 1.04 & 2.08 & $0.95 \mathrm{ab}$ & $1.30 \mathrm{ab}$ \\
\hline Uji F & tn & tn & tn & tn & $*$ & $*$ \\
\hline Interaksi & tn & tn & tn & tn & tn & $* *$ \\
\hline
\end{tabular}

Keterangan: AS: Arang sekam. *: berpengaruh nyata pada taraf uji 5\%, **: berpengaruh sangat nyata pada taraf uji $1 \%$, tn: tidak berbeda nyata pada taraf uji 5\%. Angka-angka pada kolom yang sama yang diikuti oleh huruf yang sama tidak berbeda nyata pada taraf uji 5\% (uji selang berganda Duncan). 
Tabel 7. Interaksi antara bagian batang dan media tanam terhadap panjang batang stek pohpohan berumur 4 bulan pada 6 MST

\begin{tabular}{lcccc}
\hline \multirow{2}{*}{ Bagian Batang } & Topsoil & Rockwool & $\begin{array}{c}\text { Arang Sekam }+ \\
\text { Kompos }\end{array}$ & Kascing \\
\cline { 2 - 5 } & 2.62 & \multicolumn{4}{c}{ Pertambahan Panjang Batang Stek (cm) } \\
\hline Pucuk & 2.27 & 1.07 & $3.94 \mathrm{a}$ & $3.19 \mathrm{a}$ \\
Tengah & 2.05 & 1.13 & $2.32 \mathrm{~b}$ & $2.67 \mathrm{~b}$ \\
Pangkal & tn & tn & $2.05 \mathrm{~b}$ & $2.38 \mathrm{~b}$ \\
P & tn & $* *$ \\
\hline Keterangan: & AS: Arang sekam. *: berpengaruh nyata pada taraf uji 5\%, **: berpengaruh sangat nyata pada taraf uji \\
& 1\%, tn: tidak berbeda nyata pada taraf uji 5\%. Angka-angka pada kolom yang sama yang diikuti oleh \\
& huruf yang sama tidak berbeda nyata pada taraf uji 5\% (uji selang berganda Duncan). T= Topsoil, R= \\
& Rockwool, ASK= Arang sekam + kompos, K= Kascing. T= Topsoil, R= Rockwool, ASK= Arang \\
& sekam + kompos, K= Kascing.
\end{tabular}

Tabel 8. Hasil analisis ragam perumbuhan stek batang pohpohan berumur 4 bulan

\begin{tabular}{lccccc}
\hline \multicolumn{1}{c}{ Peubah } & $\begin{array}{c}\text { Umur } \\
\text { (MST) }\end{array}$ & $\begin{array}{c}\text { Perlakuan stek } \\
\text { bagian batang }\end{array}$ & $\begin{array}{c}\text { Perlakuan } \\
\text { media tanam }\end{array}$ & Interaksi & KK (\%) \\
\hline Tinggi tunas & 5 & $0.0091^{* *}$ & $0.3750 \mathrm{tn}$ & $0.4150 \mathrm{tn}$ & 7.13 \\
& 6 & $0.0033^{* *}$ & $0.4870 \mathrm{tn}$ & $0.2526 \mathrm{tn}$ & 6.36 \\
Jumlah cabang & 5 & $0.0031^{* *}$ & $0.2103 \mathrm{tn}$ & $0.2100 \mathrm{tn}$ & 18.96 \\
& 6 & $0.0370^{*}$ & $0.5109 \mathrm{tn}$ & $0.1893 \mathrm{tn}$ & 18.05 \\
Lebar daun & 5 & $0.2876 \mathrm{tn}$ & $0.0310^{*}$ & $0.5021 \mathrm{tn}$ & 13.01 \\
& 6 & $0.1973 \mathrm{tn}$ & $0.2247 \mathrm{tn}$ & $0.3531 \mathrm{tn}$ & 13.36 \\
Diameter batang & 5 & $0.2993 \mathrm{tn}$ & $0.0116^{*}$ & $0.3300 \mathrm{tn}$ & 6.51 \\
& 6 & $0.0912^{*}$ & $0.2172 \mathrm{tn}$ & $0.3990 \mathrm{tn}$ & 6.63 \\
\hline
\end{tabular}

Keterangan: a*: berpengaruh nyata pada taraf uji $5 \%$, **: berpengaruh sangat nyata pada taraf uji $1 \%$, tn: tidak berbeda nyata pada taraf uji 5\%. Angka-angka pada kolom yang sama yang diikuti oleh huruf yang sama tidak berbeda nyata pada taraf uji 5\% (uji selang berganda Duncan).

Pada penelitian Agbo dan Obi (2008) mengenai perbanyakan stek batang tiga umur fisiologis Gongronema latifolia pada dua musim di Nsukka menunjukkan bahwa stek batang lunak Gingronema latifolia yang dilakukan pada musim kemarau dan hujan tidak mempengaruhi pertumbuhan jumlah cabang, tinggi tunas, jumlah daun, dan panjang tanaman merambat.

\section{KESIMPULAN}

Pohpohan dapat diperbanyak dengan cara perbanyakan vegetatif stek. Bahan tanam yang berasal dari pohpohan berumur 4 bulan menunjukkan nilai rata-rata terbaik pada persentase hidup, persentase berakar, jumlah daun, dan pertambahan panjang batang stek. Stek batang bagian pangkal yang ditanam pada media topsoil, rockwool, arang sekam dan kompos, serta kascing menunjukkan persentase hidup tertinggi yaitu 99.20\%, 97.73\%, $99.81 \%$, dan $98.60 \%$. Stek batang bagian pangkal yang ditanam pada media topsoil, arang sekam dan kompos, serta kascing mempengaruhi jumlah daun sebanyak 10-11 helai, 12-13 helai, dan 10-11 helai. Stek batang bagian tengah yang ditanam pada media rockwool mempengaruhi jumlah daun sebanyak 5-6 helai. Interaksi stek batang bagian pucuk yang ditanam pada media topsoil, rockwool, arang sekam dan kompos, serta kascing mempengaruhi pertambahan panjang batang stek senilai $2.62 \mathrm{~cm}, 1.28 \mathrm{~cm}$, $3.94 \mathrm{~cm}$, dan $3.19 \mathrm{~cm}$.

\section{DAFTAR PUSTAKA}

Agbo, C.U., I.U. Obi. 2008. Pettern of vegetative propagation of stem cuttings of three physiological ages of Gongronema latifolia over two seasons in Nsukka. Journal of Tropical Agriculture, Food, Environment and Extension. 7(3):193-198. 
Arinda, M. 2010. Pengaruh berbagai komposisi arang sekam dan kompos sebagai media pertumbuhan sorgum. Bul Agron. 39(4): 630-633.

[Balitsa] Balai Penelitian Tanaman Sayuran. 2007. Sayuran Indigenous Perlu Digali dan Dimanfaatkan. http://www.litbang. deptan.go.id. [19 September 2012].

[BMKG] Balai Metereologi Klimatologi dan Geofisika. 2013. Data Iklim Bulanan Stasiun Klimatologi Darmaga Bogor. http://www.bmkg.go.id//Profil/stasiunwilayah-bbmkg2.bmkg. [30 September 2013].

Hartmann, H.T., D.E. Kester. 2002. Plant Propagation Principles and Practice 7th Edition. Prentice Hall, Inc. p 632. New Jersey (US).

Ismail, A.M., A.M. D’Onghia, F. Nigro. 2011. Influence of organic growing media in combination with microbial bio-agent (clonotri or sublic) on the growth parameters of olive (Olea europaea L.) in nursery. Agric. Biol. J. N AM. 2(5): 767-772.
Landis, T.D, M. Nancy. 2009. Growing media alternatives for forest and natives plant nurseries. National Proceedings Forest and Conservation Nursery Associations [12 Februari 2008]. Department of Agriculture, Forest Service, Rocky Mountain Research Station. p 26-31; http://fs.fed.us./rm/pubs/rmrs_p058.html. United States (US). [11Januari 2013].

Mahyar, U.W. 1994. Pilea lindley. Plant Resources of South-East Asia No.8. PROSEA: Vegetables. Bogor.

Muchtadi, D. 2000. Sayur-sayuran Sumber Sehat dan Antioksidan. IPB Pr. hlm 218. Bogor.

Rahmania, R., A. Kurniawati. 2014. Penentuan ukuran stek kumis kucing (Orthosiphon aristatus Bl. Miq) dan dosis pupuk kandang pada cara tanam langsung. J. Hort. Indonesia 5(3) : 189-202

Santoso, B.B., Nasnam, Hariyadi, S. Susanto, B.S. Purwoko. 2008. Perbanyakan vegetatif tanaman jarak pagar (Jatropha curcas L.) dengan stek batang: pengaruh panjang dan diameter stek. Bul. Agron. 36(3): 255-262. 